\title{
Solar Physics Memoir Series Reinstituted
}

\author{
Ed Cliver · Lidia van Driel-Gesztelyi
}

Received: 31 October 2010 / Accepted: 31 October 2010 / Published online: 6 November 2010

(C) Springer Science+Business Media B.V. 2010

Solar Physics has reinstituted an annual series of memoirs of distinguished solar scientists. The memoir series has three main goals: $i$ ) to honor colleagues for distinguished careers, ii) to provide long-term personal perspectives on solar science; and iii) to help educate younger members of the community. Memoirists have the opportunity to: acknowledge colleagues; show pictures; share anecdotes; describe career/research strategies, tactics, and pitfalls; tell scientific detective stories including wrong turns and cul-de-sacs as well as breakthroughs; and convey what one scientist memorably called "the truly gritty, uncertain and fun nature of scientific research". They are encouraged to try and recapture what we thought then (what were the prevailing assumptions?), how we came to the present state of solar knowledge (what were the surprises?), and to point to promising paths for future research (what are the vexing puzzles, conundrums, and anomalies?).

The memoir series was inaugurated in 1996 with a memoir by Cornelius De Jager

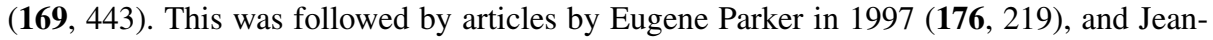
Claude Pecker in 1999 (184, 1). The series then lapsed until 2009 when a Memoir Committee consisting of Ed Cliver (Chair), Paul Charbonneau, Lyndsay Fletcher, Cristina Mandrini, Don Melrose, Giannina Poletto, Sami Solanki, Jingxiu Wang, and Bojan Vršnak, was formed from members of the Editorial Board.

E. Cliver

Air Force Research Laboratory, Space Vehicles Directorate, Hanscom AFB, MA, USA

L. van Driel-Gesztelyi ( $₫)$

Observatoire de Paris, LESIA, 92195 Meudon, France

e-mail: Lidia.vanDriel@obspm.fr

L. van Driel-Gesztelyi

UCL - Mullard Space Science Laboratory, Holmbury St. Mary, Dorking, Surrey, RH5 6NT, UK

L. van Driel-Gesztelyi

Konkoly Observatory of the Hungarian Academy of Sciences, Budapest, Hungary 
The new Committee selected Zdenek Švestka, a founding editor of Solar Physics, as the initial memoirist in the reinstated series. Zdenek's article recounting his sixty years of studying the Sun appears on page 3 of this volume. For 2011, two eminent solar scientists, Sara Martin and Einar Tandberg-Hanssen, both experts on prominences, were chosen by the Committee. Their articles will appear in the coming months. In subsequent years, the plan is to publish one memoir per year. 